\title{
Mode I and Mode II Interlaminar Fracture Toughness of Composite Laminates Interleaved with Electrospun Nanofibre Veils
}

\author{
Gareth Beckermann $^{a^{*}}$, Kim Pickering ${ }^{b}$ \\ ${ }^{a}$ Revolution Fibres, 9a Corban Ave, Henderson, Auckland, 0612, New Zealand \\ ${ }^{b}$ School of Engineering, University of Waikato, Private Bag 3105, Hamilton, New Zealand
}

\begin{abstract}
In this study, the effects of interleaved nanofibre veils on the Mode I and Mode II interlaminar fracture toughness (ILFT) of autoclave cured unidirectional carbon/epoxy composite laminates were investigated. Various electrospun nanofibre veils consisting of a range of different polymer types, fibre diameters and veil architectures were placed in the laminate mid-planes, which were subsequently subjected to double cantilever beam and end-notch flexure tests. It was found that the polymer type and veil areal weight were the most important factors contributing to laminate performance. A $4.5 \mathrm{~g} / \mathrm{m}^{2}$ PA66 veil provided the best allround performance with fracture toughness improvements of $156 \%$ and $69 \%$ for Mode I and Mode II, respectively.
\end{abstract}

Keywords: A. Carbon-carbon composites, B. Fracture toughness, D. Mechanical Testing, Electrospinning

\section{Introduction}

The benefits of fibre reinforced polymer composites are well known and their use has become commonplace in "high tech" applications requiring low weight as well as high strength, high stiffness and corrosion resistance. Despite these attributes, fibre reinforced composites generally suffer from poor impact resistance, poor fracture toughness and poor delamination strength. This is particularly the case when brittle

\footnotetext{
${ }^{*}$ Corresponding author. Tel.: +64 98354805

E-mail address: gareth@revolutionfibres.com
} 
thermosetting resins are used as the composite matrix. Currently, these problems are addressed by adding toughening particles to the matrix resin, or by inserting tough polymer films or microfibre interleaves (veils) into the interlayers between the plies of the laminate.

Toughening particles in the micro or nano-scale range can be made from thermoplastic polymers, rubbers, elastomers or carbon, and are currently blended into epoxy resins to improve toughness. They are generally difficult to disperse evenly in the resin and can form regions of high and low particle concentrations which can reduce the performance of the composite. Furthermore, toughening particles are also free to flow with the resin during the curing process resulting in further uneven particle distribution. Toughening particles also increase resin viscosity, making them particularly unsuitable for laminates fabricated using out of autoclave processing methods [1], and can increase laminate thickness, decrease in-plane stiffness and strength and potentially lower the glass transition temperature $\left(T_{g}\right)$ of the laminate [2].

Composite toughening using a polymer film in the interlayer can result in poor resin flow, porosity and poor adhesion between the resin and the film, and this method is not generally suitable for use in conjunction with liquid moulding methods [3]. In addition to this, prepreg materials that incorporate interleaving films tend to be stiff, tack-free and are difficult to use.

Microfibre interleaving veils used in laminates can improve impact resistance but often have detrimental effects on other composite mechanical and physical properties. Furthermore, the addition of bulky microfiber veils can result in undesirable increases in weight and thickness in the laminate.

It is proposed that a lightweight veil made from nano-sized thermoplastic fibres could be used as an alternative to currently used composite toughening methods. Nanofibre membranes have the advantage of being highly porous and thus do not impede the flow of resin during cure. They have very high specific surface areas to promote good bonding with the matrix resin and are thin and lightweight such that they do not significantly affect laminate thickness and weight. 
Electrospun thermoplastic nanofibre interleaving veils have been shown to have a positive influence on the in-plane mechanical properties of laminates such as reducing impact damage and increasing delamination onset life [2]. It has also been shown that certain nanofibre veils can be used to improve the compression after impact (CAI) [4], delamination resistance and the Mode I [5] and Mode II interlaminar fracture toughness (ILFT) of composites [6-10]. Nanofibre veils have also been shown to improve the fatigue resistance $[2,11]$ and vibration damping [12] properties of fibre reinforced composite materials. It is also possible to make electrically conductive nanofibre veils for composite applications such as aircraft structures and wind turbines where improved through thickness electrical conductivity and lightning strike protection are required $[13,14]$.

Nanofibre veils have the potential to out-perform many of the existing composite toughening mechanisms mentioned above. Magniez et.al. [15] showed that composites interleaved with polyvinylidene fluoride (PVDF) nanofibre veils outperformed laminates interleaved with films of the same areal weight and polymer grade when it came to Mode I and Mode II interlaminar fracture toughness. Li et.al. [7] showed that composites interleaved with polysulfone (PSU) nanofibre veils had better Mode I interlaminar fracture toughness, flexural strength and flexural modulus when compared to similar laminates interleaved with PSU film . PVDF is an example of a polymer that is non-miscible in an epoxy matrix during cure and remains as nanofibre in the cured laminate, and PSU is a polymer that dissolves in an epoxy matrix during cure and forms particles in the resin after an inhomogeneous phase separation.

Nanofibre veils may also perform better than microfibre veils of the same areal weight. Tsotsis [3] showed that compression after impact (CAI) could be improved for composite laminates by reducing the size of the interleaving veil fibres. His reasoning for this was that with a greater number of filaments per unit area, any crack would have to go up, over, around, or through a greater number of filaments. Thus, lateral (in between the plies) crack growth would require a greater amount of energy to propagate a unit area of new crack growth than a material with fewer filaments at the same areal weight. Zhang et al [16] also showed that veils consisting of smaller nanofibres $(450 \mathrm{~nm})$ produced better results for Mode I Interlaminar shear strength (propagation), flexural strength and flexural modulus than veils consisting of larger nanofibres (950nm). In 
some instances, mixed nanofibre veils combining one type on nanofibre that performs well in Mode I loading and another that performs well in Mode II loading can result in a higher toughening effect than if the nanofibres were used separately [10]. It has been noted that not much work has been reported in the literature to compare the effects of veils made from different polymer types and different veil architectures.

In this investigation, the Mode I and Mode II ILFT of a range of different autoclave cured unidirectional carbon/epoxy composite laminates interleaved with continuous non-woven electrospun thermoplastic nanofibre veils were examined. In Mode I, the pre-cracked laminate failure is governed by peel forces and is evaluated by means of the double cantilever beam test. In Mode II, the crack is propagated by shear stresses and is evaluated by means of the end-notch flexure test. The effects of the veil polymer type, fibre diameter and veil architecture were investigated.

Five ductile polymer types were selected for this investigation: Polyamide 6'6 (PA66), Polyvinyl butyral (PVB), Polycaprolactone (PCL), Polyethersulfone (PES) and Polyamide-imide (PAI). These polymers were selected to provide veils with a wide range of mechanical and physical properties that could influence the toughness of composites. PA66 is known to bond well to epoxy resin, and has a high fracture toughness and strain to failure rate. PVB has good adhesive properties and a high fracture toughness. PCL has a melting temperature below the cure temperature of the resin, resulting in a phase separation and the formation of spherical polymer particles in the matrix after cure [10]. PCL also has a very high strain to failure. PES has a low strain to failure and a very low fracture toughness, but has good tensile properties. PAI has a very high tensile strength, tensile modulus and fracture toughness. PA66 was also modified with the inclusion of silver nanoparticles to increase the stiffness and hardness of the polymer. Each of these polymers can be electrospun at a rate that would be suitable for mass scale production.

The effect of different veil fibre diameters was also investigated, as well as veils consisting of mixed polymer types and fibre diameters.

\section{Experimental}




\subsection{Materials}

\subsubsection{Polymers and Solvents}

Various polymer and solvent solutions were prepared for electrospinning using the following materials: PA66 (BASF Ultramid A3k); PVB (Kuraray Mowital B60H); PCL (Polymorph); PES (BASF Ultrason E6020P); PAI (Solvay Torlon 4000T-HV); Formic acid (FA, 99\% analytical grade); Acetic acid (AA, glacial reagent grade); Ethanol (ETH, 96\% reagent grade); Dimethylacetamide (DMA, 99.9\% HPLC grade) and Dimethylformamide (DMF, 99.9\% HPLC grade).

\subsubsection{Composite Materials}

MTM57/T700S(24K)-300-35\%RW unidirectional prepreg (supplied by Umeco) was used to manufacture the composite test specimens. The MTM57 resin system used in the prepreg is a toughened $120^{\circ} \mathrm{C}$ curing epoxy.

\subsection{Electrospinning of Nanofibre Veils}

Nanofibre veils were manufactured by means of the electrospinning process, which is one of the most commonly used techniques for the mass-production of polymer nanofibres and has been explained in detail by Rutledge and Fridrikh [17]. Non-woven veils were fabricated using a unique needle-less electrospinning process developed by Revolution Fibres for the large scale manufacture of nanofibre materials.

Polymeric electrospinning solutions were made by dissolving a specified quantity of polymer into a suitable solvent or solvent blend, and then mixing the solution until the polymer had completely dissolved. The solution constituents that were used make the nanofibre veils used in this investigation can be seen in Table 1. 
During the electrospinning process, droplets of a polymer solution were applied to the positively charged electrodes of the electrospinning machine. The polymer solution was then drawn and spun through an electrostatic field before being deposited as randomly oriented nanofibres onto a wax paper substrate, resting on a negatively charged collector plate. Non-beaded nanofibre veils of varying areal weights were fabricated for use in the interleaved composites, some of which can be seen in Figure 1. Areal weights were determined by weighing $100 \mathrm{~mm} \times 100 \mathrm{~mm}$ samples using a Precisa XB220A analytical balance and then dividing the sample mass by the sample area.

\subsection{Fabrication of Composite Panels and Test Specimens}

Composite panels were prepared in accordance with the methods stated in ASTM D5687/D5687M [18]. Composite panels were fabricated by means of hand-stacking 12 plies of unidirectional MTM57/T700S(24K)$300-35 \%$ RW prepreg in a $0^{\circ}$ orientation. During the process, the nanofibre veils were placed into the midplane of the laminates along with a release-agent coated aluminium foil insert ( $10 \mu \mathrm{m}$ thickness) to induce the initial delamination. The nanofibre veils that were evaluated in the test panels are summarised in Table 2. As can be seen in Table 2, some of the veils had to be stacked with multiple plies of nanofibre to get the desired areal weight. Panel 5 and Panel 6 contained veils made up of alternating layers of PA66 and PVB, and Panel 7 contained PVB microfibers (700-1000nm fibre diameter) rather than nanofibres (400-700nm fibre diameter) as used in Panel 8. Panel 9 consisted of a PA66 veil containing silver nanoparticles (nano-scale $\mathrm{AgNO}_{3}$ precipitates) distributed throughout the polymer nanofibres.

After the layup, panels were cured in a vacuum bag within an autoclave using a stepped cure cycle with a dwell step of $80^{\circ} \mathrm{C}$ for 60 minutes followed by a cure temperature of $120^{\circ} \mathrm{C}$ for 90 minutes. A full vacuum and an autoclave pressure of 3.5 bar were maintained during curing of the panels. Test specimens were cut from the cured panels by means of water jet cutting. Cured panel thicknesses were found to be approximately 3.6 $\mathrm{mm}$ for all panels. SEM Images of transverse sections of typical laminates interleaved with PA66 nanofibre veils are provided in Figure 2(a), (b) and (c). It can be seen in the images that the thermoplastic nanofibres are not visible in the matrix resin at these magnifications and the interlayer regions increased slightly in 
thickness when the veil areal weights were increased. Typical interlayer thicknesses of $28 \mu \mathrm{m}, 34 \mu \mathrm{m}$ and $50 \mu \mathrm{m}$ were observed for laminates interleaved with PA66 veils of $1.5 \mathrm{~g} / \mathrm{m}^{2}, 4.5 \mathrm{~g} / \mathrm{m}^{2}$ and $9 \mathrm{~g} / \mathrm{m}^{2}$, respectively. The interlayer thickness increases associated with increasing the veil areal weight were thought to have had a negligible effect on cured laminate thickness. Another observation from Figure 2 is that the toughened interlayers appear homogenous and do not show any evidence of voids. These veils are made from PA66 which is considered somewhat hygroscopic, and it is thought that any water absorbed into the PA66 would vaporise during the cure process resulting in void formation in the resin. This does not appear to have occurred, and it seems as though the amount of water introduced into the laminate by means of the PA66 veils is insufficient to cause visible void formation.

Double Cantilever Beam (DCB) test specimens (Figure 3) were prepared from the cured laminate panels in accordance with ASTM D 5528 [19] using the following dimensions: width $b=20 \mathrm{~mm}$, nominal thickness $h=$ $3.7 \mathrm{~mm}$, and initial crack length $a_{o}=50 \mathrm{~mm}$. The piano hinges (used to hold the specimens in the jaws of the test machine) and the specimen outer surfaces were scuffed to assist adhesion and were bonded together under pressure using a cyanoacrylate adhesive. The artificial crack ends (insert end) were located and marked on the sides of each specimen. White correction fluid was then applied to one side of each specimen and $1 \mathrm{~mm}$ interval markings were then made from the start of the insert film up to a distance of $50 \mathrm{~mm}$.

End Notch Flexure (ENF) test specimens (Figure 4) were prepared using the following dimensions: width $b=$ $20 \mathrm{~mm}$, nominal thickness $2 h=3.7 \mathrm{~mm}$, and initial crack length $a_{o}=40 \mathrm{~mm}$. The half span length, $L$, was $50 \mathrm{~mm}$. The end of the insert was located and a mark was made on one side of the specimen at distance $a_{0}=$ $40 \mathrm{~mm}$ from the insert end. Additional marks were made on the specimen at distances of $+10 \mathrm{~mm}$ and $-10 \mathrm{~mm}$ from this mark to use as guides for positioning the specimen in relation to the supports during compliance calibration loadings.

\subsection{Double Cantilever Beam Test}


Double Cantilever Beam tests were performed using an Instron 33R4204 universal testing machine fitted with a $5 \mathrm{kN}$ load cell, and the method used was based on the ASTM D 5528 standard test method [19]. Four control specimens were tested, and three specimens were tested for each type of nanofibre veil. Test specimens were clamped in the jaws of the test machine via the bonded piano hinges, and specimens were loaded at a rate of $1 \mathrm{~mm} / \mathrm{min}$ whilst the load-displacement data was recorded. Each specimen was initially loaded to the point of failure, and the crack was allowed to propagate a short distance (generally around 3$5 \mathrm{~mm}$ ) before the specimen was unloaded. The load and displacement at which the straight line part of the load-displacement plot starts to deviate were recorded for the first loading, and these values were used to determine the onset Mode I failure at the insert, $\left(G_{l c-\text { onset }}\right.$ Insert). Thereafter, without removal from the test machine jaws, the specimen was reloaded until a final delamination length of $50 \mathrm{~mm}$ was reached. The load and displacement at which the straight line part of the plot starts to deviate were recorded for the second loading, and these values were used to determine the onset Mode I failure after the specimen had been precracked, (Glc-onset Pre-crack). As the crack propagated past each mark on the side of the specimen (Figure 5), the load and displacement from the test machine were recorded so that the propagation ILFT could be calculated at each point. The Mode I propagation ILFT, $\left(G_{I c-P r o p}\right)$, was then determined by taking the average of these points.

The Modified Beam Theory data reduction method as stated in the ASTM standard [19] was used to calculate the values for " $G_{l c-o n s e t} I n s e r t$ ", "G $G_{l c-o n s e t}$ Pre-crack" and " $G_{l c-P r o p}$ " using Equation 1:

$$
G_{I}=\frac{3 P \delta}{2 b(a+|\Delta|)}
$$

Where $G$, is the Mode I interlaminar fracture toughness, $P$ is the applied load, $\delta$ is the load point displacement, $b$ is the specimen width, $a$ is the delamination length (crack length), $\Delta$ is a value that is determined experimentally by generating a least squares plot of the cube root of compliance $\left(C^{1 / 3}\right)$ as a function of delamination length.

\subsection{End Notch Flexure Test}


End Notch Flexure tests were performed using an Instron 33R4204 universal test machine fitted with a $5 \mathrm{kN}$ load cell. Six control specimens were tested, and five specimens were tested for each type of nanofibre veil. Specimens were not pre-cracked prior to testing. The method is based on previous work done by O'Brien et al. [20] and Zhu et al. [21] using a 3-point bend fixture with a $10 \mathrm{~mm}$ diameter loading nose and side supports (Figure 6), and involved three loadings per specimen performed at a loading rate of $0.5 \mathrm{~mm} / \mathrm{min}$. The first two loadings were required for compliance calibration of the system and were performed at sub failure loads $(150 N)$ to prevent crack propagation in the specimen. The final loading was performed to initiate the crack propagation and was continued until complete failure of the specimen occurred (rapid crack progression). For the first two loadings, the specimen was positioned such that the $a_{0}-10 \mathrm{~mm}$ and $a_{0}+10 \mathrm{~mm}$ marks were situated above one of the lower fixture supports (Figure 4). The final loading was performed when the specimen was positioned such that the ao mark was situated above one of the lower fixture supports.

A compliance calibration method was used for data reduction [21]. The compliance of the specimen $(C)$ at each initial crack length (i.e. the mark at $a_{0}-10 \mathrm{~mm}$, $a_{0}$ or $a_{0}+10 \mathrm{~mm}$ ) was obtained by taking the gradient inverse of the linear portion of the load vs displacement curve obtained from each loading (taken between $30 \mathrm{~N}$ and $150 \mathrm{~N})$. Equation 2 was used to fit the compliance vs. crack length data.

$$
C\left(8 b h^{3}\right)=A+B a_{0}^{3}
$$

where $a_{0}$ is the initial crack length, $b$ is the specimen width and $h$ is half the thickness.

Parameters $A$ and $B$ were determined experimentally for each specimen and taken from the intercept $(A)$ and slope $(B)$ of a straight line fitted to the data points in a $C\left(8 b h^{3}\right)$ vs. $a^{3}$ plot by linear least squares (Figure 7).

The Mode II interlaminar fracture toughness $\left(G_{I I c}\right)$ onset values were calculated using the compliance calibration method in Equation 3. 


$$
G_{I I c}=\frac{3 P_{c}^{2}}{2 b} \frac{B}{8 b h^{3}} a_{0}^{2}
$$

where $P_{c}$ is the maximum load at the critical point where complete failure of the specimen occurred.

\subsection{Microscopy}

Fracture surfaces of test specimens were examined and imaged using an Olympus BX60F5 metallurgical microscope and a WILD M3B stereo microscope (both fitted with a Nikon Digital Sight DS-SMc digital camera), and a Hitachi S-4700 Field Emission Scanning Electron Microscope.

\section{Results and Discussion}

\subsection{Double Cantilever Beam Tests and Mode I ILFT Determination}

DCB tests were performed on various non-interleaved and interleaved laminates, and typical loaddisplacement curves for each can be seen in Figure 8. For the first loading, the control specimen (Figure 8a) and the PCL interleaved laminate (Figure 8j) showed linear elastic behaviour, but a slight non-linearity was observed before the load reached its maximum. The load-displacement curves of nanofibre interleaved laminates typically showed linear elastic behaviour up to the point of maximum load, after which the load dropped sharply. This drop in peak load corresponds with the onset Mode I failure at the insert and corresponds with crack initiation and growth in the interlayer.

Typical Mode I resistance curves (R-curves) can be seen in Figure 9 and were calculated from the loaddisplacement curves and the incremental delamination length measurements using the MBT method. The onset Mode I failure at the insert, $\left(G_{l c-o n s e t}\right.$ Insert), the onset Mode I failure after the specimen had been precracked, $\left(G_{l c-\text { onset }}\right.$ Pre-crack), and the Mode I propagation ILFT, $\left(G_{I c-P r o p}\right)$, can all be seen on the R-curves provided. 
When looking at Figure 9, it can be seen that R-curves of laminates reinforced with PA66 nanofibre veils (Figure $9 b, c, d, i)$ are different to the others in the sense that $G_{1 c}$ starts off at a high level and then decreases during the early stages of crack growth. This observation has also been reported by Kageyama et al [22] and Hojo et al $[23,24]$ for interlayer toughened laminates. For these PA66 nanofibre interleaved laminates, the high initial fracture toughness experienced at the insert film, $\left(G_{l c-o n s e t} I n s e r t\right)$, is due to the high loading required to initiate crack propagation in the toughened interlayer. Once crack growth has been initiated, the fracture toughness then decreases as the crack transitions from the toughened interlayer region to the untoughened interlayer/base lamina interface.

Optical micrographs of the fracture surfaces of DCB specimens interleaved with PA66 nanofibre veils can be seen in Figure 10(b) and Figure 10(c) and provide further evidence of crack path transitions. Plastic deformation of the matrix and the nanofibre veils can be seen (light coloured regions) and typical brittle interlaminar and intralaminar fracture surfaces are also visible (darker coloured regions). Both surface topographies show brittle and ductile fracture regions which highlight the complex micro mechanisms of failure. It can be seen in both images that the cracks were initiated in the nanofibre veil (light coloured regions), but after a distance of approximately $6 \mathrm{~mm}$ the crack transitioned into the interlayer/base lamina interface (darker coloured regions) and also into the base lamina (where the carbon fibres can be seen). The crack is more likely to follow the path of least resistance in the laminate, therefore it is inclined to move out of the toughened interlayer and into a less tough region.

Once the crack had transitioned from the toughened interlayer, the fracture toughness of PA66 nanofibre interleaved laminates became similar to those of non-interleaved laminates, as can be seen by the similarities in the "propagation" $G_{l c}$ values of the R-curves in Figure 9.

The control laminate and laminates interleaved with other veils typically show conventional R-curves where the $\mathrm{G}_{\mathrm{Ic}}$ remains fairly constant or increases as the crack propagates through the interlayer in the early stages of delamination. These laminates are generally characterised as having relatively low $G_{l c-o n s e t}$ Pre-crack values, and the crack appears to remain stable and progresses through the interlayer region which may be 
the path of least resistance. Optical micrographs of the fracture surfaces of laminates interleaved with PES and PAI veils can be seen in Figure 10(f) and Figure 10(g), respectively. These are examples of laminates that are characterised by low fracture toughness values in the early stages of delamination and it can be seen in the micrographs that the delamination progressed through the ductile nanofibre veil without transitioning into other regions of the laminate.

The Mode I critical strain energy release rate values as determined by means of the MBT method are summarised in Table 3. For each laminate tested, three variants of $\mathrm{G}_{\mathrm{IC}}$ were determined. Since delamination was initiated in the mid-plane of the interlayer by means of a foil insert, the initial value of the Mode I fracture toughness, ( $G_{l c \text { - onset }}$ Insert), indicates the $G_{l c}$ of the interlayer [22]. Since it has been shown that the crack can transition from the interlayer into other regions of the laminate, the other fracture toughness measurements, ( $G_{l c-\text { onset }}$ Pre-crack and $\left.G_{l c-P r o p}\right)$, may not give a true measure of the toughness of the interlayer. Hence, the values for $G_{l c \text { - onset }}$ Insert have been used to evaluate and compare the performance of laminates in this investigation.

From the results in Table 3, it can be seen that laminates interleaved with PA66 veils provided the greatest improvements over the non-interleaved control when considering the onset Mode I failure at the insert, $\left(G_{l c}\right.$ onset Insert), with improvements ranging from $55 \%$ to $173 \%$ being observed. It can also be seen that the $G_{l c-}$ onset Pre-crack and $G_{l c-P r o p}$ values for these laminates are very similar to those of the control, suggesting that once the delamination leaves the toughened interlayer it experiences a similar Mode I critical strain energy release rate to a delamination in a non-interleaved laminate.

PVB and PCL nanofibre veil interleaved laminates showed slight improvements in fracture toughness when compared to the control, but PES and PAI veils resulted in reductions in laminate fracture toughness.

The effect of veil areal weight on the Mode IILFT, ( $G_{i c}$ - onset Insert), for composites interleaved with various PA66 veils can be seen in Figure 11. It can be seen that the relationship between veil areal weight and $G_{\mathrm{lc}}$ is linear up to $4.5 \mathrm{gm}^{2}$, after which it trails off. The $3.8 \mathrm{~g} / \mathrm{m}^{2} \mathrm{PA} 66+\mathrm{AgNO}_{3}$ laminate was included in the plot 
shown in Figure 11 and the results fitted well to the data trend. This suggests that the $\mathrm{AgNO}_{3}$ nanoparticles that were added to the nanofibre polymer didn't have any significant influence on the fracture toughness of the veil. It was thought that the stiffness and hardness of the PA66 nanofibre veil could be altered with the addition of $\mathrm{AgNO}_{3}$ nanoparticles, but this has not translated into any change in the fracture toughness performance of this veil.

Two laminates containing multi-polymer veils were evaluated. The first was interleaved with a $9 \mathrm{~g} / \mathrm{m}^{2}$ veil consisting of 6 alternating layers of PA66 nanofibres and PVB microfibres, and the second was interleaved with a $9 \mathrm{~g} / \mathrm{m}^{2}$ veil consisting of a core of PA66 nanofibres with skins made up of PVB microfibres. From the results in Table 3 it can be seen that the veil configurations did not result in any significant differences in laminate toughness when compared to each other, but the combinations of PA66 nanofibres and PVB microfibers resulted in reduced toughness when compared to laminates interleaved with PA66 and PVB monopolymer veils.

The effect of veil fibre diameter on laminate toughness was evaluated. As can be seen in Table 3, laminates interleaved with $4.5 \mathrm{~g} / \mathrm{m}^{2}$ PVB microfibres (700 - 1000 nm diameter range) were not significantly different to laminates interleaved with $4.3 \mathrm{~g} / \mathrm{m}^{2}$ PVB nanofibres (400-700nm diameter range). This suggests that veil fibre diameter variations in the nanometre range do not influence laminate fracture toughness.

\subsection{End Notch Flexure Tests and Mode II ILFT Determination}

Table 4 shows the crack initiation Mode II critical strain energy release rates for nanofibre interleaved laminates. It can be seen that PA66 showed the best fracture toughness results of all the veils tested, with a $69 \%$ improvement over the control being observed for the $4.5 \mathrm{~g} / \mathrm{m}^{2}$ PA66 nanofibre interleaved laminate. PAI also performed well with a G॥c improvement of $56 \%$. The two PVB veils performed poorly and both showed a decrease in Gıc. The G॥c results of the two PVB veils were similar enough to suggest that veil fibre diameter did not greatly influence the Mode II fracture toughness of the laminate. The two laminates containing 9 $\mathrm{g} / \mathrm{m}^{2}$ multi-polymer veils (alternating layers of PA66 nanofibres and PVB microfibres) showed slightly lower 
results for Gıc when compared to laminates interleaved with a $9 \mathrm{~g} / \mathrm{m}^{2}$ PA66 veil. The order in which the PA66 nanofibre and PVB microfiber layers were placed in the veil did not appear to affect laminate Mode II fracture toughness. It was also observed that the PCL and PES veils did not significantly improve laminate $\mathrm{G}_{\| \mathrm{C}}$.

The Mode II ILFT of composites interleaved with various PA66 veils can be seen in Figure 12, and it can be seen that G॥c increased as the nanofibre areal weight increased up to what appeared to be the optimum value of $4.5 \mathrm{~g} / \mathrm{m}^{2}$, after which a slight reduction was observed. It is thought that the PA66 veils outperformed those made from other polymers due to a combination of the high toughness of the PA66 polymer and also the compatibility of PA66 with the epoxy resin matrix in the laminates.

It appears as though the Mode II failures of the PA66 nanofibre interleaved laminates were similar to those of the Mode I failures in the sense that the loads required to initiate crack propagation in the toughened interlayer regions were high, but decreased rapidly as the cracks moved into the less tough intralaminar zones.

\subsection{Influence of Polymer Type on Fracture Toughness}

For an interleaved material to improve the ILFT, the polymer needs to bond well to the matrix resin [25], it needs to be tough [24], have a high shear strength [15] and it needs to be able to plastically deform in a ductile manner [26]. However, it is quite common for interleaves of the same polymer to perform very differently in Mode I and Mode II ILFT testing [10], suggesting that some material properties can have a positive or a negative influence on each mode of ILFT failure. Both modes of failure are complex, with Mode I being dominated by peel forces and Mode II being dominated by shear forces, and it is difficult to determine which material properties or combinations thereof are most likely to affect fracture toughness.

When considering the DCB test results, it was observed that there seemed to be a correlation between Mode I ILFT and the elongation to break of the bulk polymers used to make the nanofibre veils. Elongation to break is a measure of the ductility of a material. PES and PAI performed poorly in the Mode I DCB tests, possibly 
due to the comparatively low elongation to break properties of the bulk polymer ( $6.7 \%$ and $7.6 \%$, respectively ${ }^{1}$ ), whereas bulk PA66 and PVB have comparatively high elongation to break properties ( $30 \%$ and $33 \%$, respectively ${ }^{1}$ ) and performed well in the Mode I DCB tests. It is thought that the plastic deformation of the nanofibre veils diminished the crack energy through the interlayer and thus increased the Mode I ILFT. Fracture surfaces of tested DCB specimens can be seen in Figure 10. The non-interleaved control (Figure 10(a)) shows a typical brittle failure usually seen with epoxy resin, whereas specimens interleaved with PA66 (Figure 10(b) and (c)) and PVB (Figure 10(d)) veils exhibit evidence of ductile failure in the interlayer near to where the crack growth was initiated. A brittle fracture surface can be seen after the ductile regions in each specimen where the crack moved out of the toughened interlayer and into the untoughened interlayer/base lamina interface regions. Specimens interleaved with PES (Figure 10(f)) and PAI (Figure 10(g) veils do not show the same ductile failure, and instead show a comparatively smooth fracture surface where the crack cleaved through interleaved interlayer without diverting into other regions. PCL has a very high elongation to break (679-948\%), but due to its low melting point $\left(60^{\circ} \mathrm{C}\right)$ it completely melts and dissolves into the epoxy resin during the curing process rather than remaining as a nanofibre veil. No significant improvement in Mode I ILFT was seen for PCL interleaved laminates, and the fracture surface seen in Figure 10(e) shows a typical brittle failure with no visible evidence of any ductile PCL phases in the resin.

When considering the ENF test results, it was observed that there seemed to be a correlation between Mode II ILFT and the tensile strength of the bulk polymers used to make the nanofibre veils. PVB and PCL performed poorly in the Mode II ENF tests, possibly due to the comparatively low tensile strength of the bulk polymer (36 MPa and $9 \mathrm{MPa}$, respectively ${ }^{1}$ ), whereas bulk PA66, PES and PAI have comparatively high tensile strengths ( $85 \mathrm{MPa}, 90 \mathrm{MPa}$ and $152 \mathrm{MPa}$, respectively ${ }^{1}$ ) and performed well in the Mode II ENF tests. According to Xia and Hutchinson [27], Mode II failure occurs as a result of combined shear and tensile microcrack growth. While the toughening mechanisms of this type of system are still not fully understood, it is believed that the nanofibres act to bridge the microcracks which form in the interlayer during Mode II fracture. Such bridging absorbs crack energy, and it is thought that as long as the nanofibers are well bonded

\footnotetext{
${ }^{1}$ Bulk polymer elongation to break properties were obtained from the manufacturer's technical data sheets.
} 
to the matrix resin, a nanofibre veil with a higher tensile strength will provide better resin reinforcement and will thus better resist the opening of these microcracks resulting in a higher Mode II ILFT.

\section{Conclusions}

In this investigation it was shown that the Mode I and Mode II ILFT of autoclave cured unidirectional carbon/epoxy composite laminates could be significantly improved by interleaving the laminates with lightweight thermoplastic nanofibre veils. In real world scenarios, composite laminates may experience situations where loadings on the laminate may induce both modes of failure. It is therefore important for an interleaved laminate to be effective under both Mode I and Mode II loading conditions. A range of different veils were considered, and it was found that a $4.5 \mathrm{~g} / \mathrm{m}^{2}$ PA66 veil provided the best all-round fracture toughness performance with improvements of $156 \%$ for Mode I and $69 \%$ for Mode II being observed. It is likely that the ability of the PA66 veils to absorb fracture energy is linked to the compatibility of PA66 with the epoxy matrix and the high intrinsic toughness, strength and ductility of the polymer.

\section{Acknowledgements}

The authors would like to thank Rosalie Collins-Gargan from the University of Waikato for providing the SEM images used in this paper.

\section{References}

1. Kuwata M and Hogg P.J. Interlaminar toughness of interleaved CFRP using non-woven veils: Part 1. Mode-I testing. Composites Part A: Applied Science and Manufacturing, 2011. 42(10): p. 1551-1559.

2. Shivakumar K, et al. Polymer Nanofabric Interleaved Composite Laminates. AIAA, 2009. 47(7).

3. Tsotsis T.K. Interlayer toughening of composite materials. Polymer composites, 2009. 30(1): p. 7086. 
4. Akangah P and Shivakumar K. Assessment of Impact Damage Resistance and Tolerance of Polymer Nanofiber Interleaved Composite Laminates. Journal of Chemical Science and Technology, 2013. 2(2).

5. Kim J-S and Reneker DH. Mechanical Properties of Composites Using Ultrafine Electrospun Fibers. Polymer Composites, 1999. 20(1).

6. Zhang J, et al. Phase morphology of nanofibre interlayers: Critical factor for toughening carbon/epoxy composites. Composites Science and Technology, 2012. 72(2): p. 256-262.

7. Li G, et al. Inhomogeneous toughening of carbon fiber/epoxy composite using electrospun polysulfone nanofibrous membranes by in situ phase separation. composites science and technology, 2008. 68(3-4): p. 987-994.

8. Palazzetti R, et al. Influence of electrospun Nylon 6,6 nanofibrous mats on the interlaminar properties of Gr-epoxy composite laminates. Composite Structures, 2012. 94(2): p. 571-579.

9. Hamer S, et al. Mode I interlaminar fracture toughness of Nylon 66 nanofibrilmat interleaved carbon/epoxy laminates. Polymer composites, 2011. 32(11): p. 1781-1789.

10. Saghafi $\mathrm{H}$, et al. The effect of interleaved composite nanofibrous mats on delamination behavior of polymeric composite materials. Composite Structures, 2014. 109: p. 41-47.

11. Phong N.T, et al. Improvement in the mechanical performances of carbon fiber/epoxy composite with addition of nano-(Polyvinyl alcohol) fibers. Composite Structures, 2013. 99: p. 380-387.

12. Palazzetti R, Zucchelli A, and Trendafilova I. The self-reinforcing effect of Nylon 6,6 nano-fibres on CFRP laminates subjected to low velocity impact. Composite Structures, 2013. 106: p. 661-671.

13. Guo M, et al. Simultaneously increasing the electrical conductivity and fracture toughness of carbon-fiber composites by using silver nanowires-loaded interleaves. composites science and technology, 2014. 97: p. 27-33.

14. Kumar S, et al. Highly dispersed and electrically conductive polycarbonate/oxidized carbon nanofiber composites for electrostatic dissipation applications. Carbon, 2010. 48(13): p. 3846-3857.

15. Magniez K, De Lavigne C, and Fox B.L. The effects of molecular weight and polymorphism on the fracture and thermo-mechanical properties of a carbon-fibre composite modified by electrospun poly (vinylidene fluoride) membranes. Polymer, 2010. 51(12): p. 2585-2596. 
16. Zhang J, Lin T, and Wang X. Electrospun nanofibre toughened carbon/epoxy composites: Effects of polyetherketone cardo (PEK-C) nanofibre diameter and interlayer thickness. composites science and technology, 2010. 70(11): p. 1660-1666.

17. Gregory C. Rutledge S.V.F. Formation of fibers by electrospinning. Advanced drug delivery reviews, 2007. 59: p. 1384 - 1391.

18. ASTM D5687/D5687M - Guide for Preparation of Flat Composite Panels with Processing Guidelines for Specimen Preparation. 2007.

19. ASTM ASTM D 5528 - Standard Test Method for Mode I Interlaminar Fracture Toughness of Unidirectional Fiber-Reinforced Polymer Matrix Composites. 2007.

20. O'Brien T.K, Johnston W.M, and Toland GJ.. Mode II Interlaminar Fracture Toughness and Fatigue Characterization of a Graphite Epoxy Composite Material. NASA Center for AeroSpace Information, 2010. NASA/TM-2010-216838.

21. Zhu Y, Bakis C.E, and Adair J.H. Effects of carbon nanofiller functionalization and distribution on interlaminar fracture toughness of multi-scale reinforced polymer composites. Carbon, 2012. 50(3): p. 1316-1331.

22. Kageyama K, et al. Mode I and Mode II Delamination Growth of Interlayer Toughened Carbon/Epoxy (T800H/3900-2) Composite System, in Composite Materials: Fatigue and Fracture, R.H. Martin, Editor 1995, ASTM.

23. Hojo $\mathrm{M}$, et al. The role of interleaf/base lamina interphase in toughening mechanism of interleaftoughened CFRP. in ICCM-12. 1999. Paris.

24. Hojo M, et al. Mode I delamination fatigue properties of interlayer-toughened CF/epoxy laminates. Composites Science and Technology, 2006. 66(5): p. 665-675.

25. K. N. Shivakumar, et al. Compatibility assessment between interleaving nanofibers and composite laminates, in ICCM192013: Montreal, Canada.

26. Groleau MR, et al. Mode II fracture of composites interleaved with Nylon particles. composites science and technology, 1996. 56.

27. Xia Z.C and Hutchinson J.W. Mode II fracture toughness of a brittle adhesive layer. International Journal of Solids and Structures, 1994. 31(8) 
Table 1: Polymer solutions and nanofibre diameters

\begin{tabular}{lll}
\hline $\begin{array}{l}\text { Nanofibre } \\
\text { Polymer }\end{array}$ & $\begin{array}{l}\text { Polymer/Solvent Solution } \\
(\% \mathbf{w} / \mathbf{w})\end{array}$ & $\begin{array}{l}\text { Fibre Diameters } \\
(\mathbf{n m})\end{array}$ \\
\hline PA66 & $15 \%$ PA66 + 68\% FA + 17\% AA & $150-300$ \\
PVB & $10 \%$ PVB + 90\% ETH & $400-700$ \\
PVB & $10 \%$ PVB + 85\% ETH & $700-1000$ \\
PCL & $13 \%$ PCL + 70\% FA + 17\% AA & $150-300$ \\
PES & $20 \%$ PES + 80\% DMA & $150-300$ \\
PAI & $15 \%$ PAI + 77\%DMA + 8\%DMF & $150-300$ \\
\hline
\end{tabular}
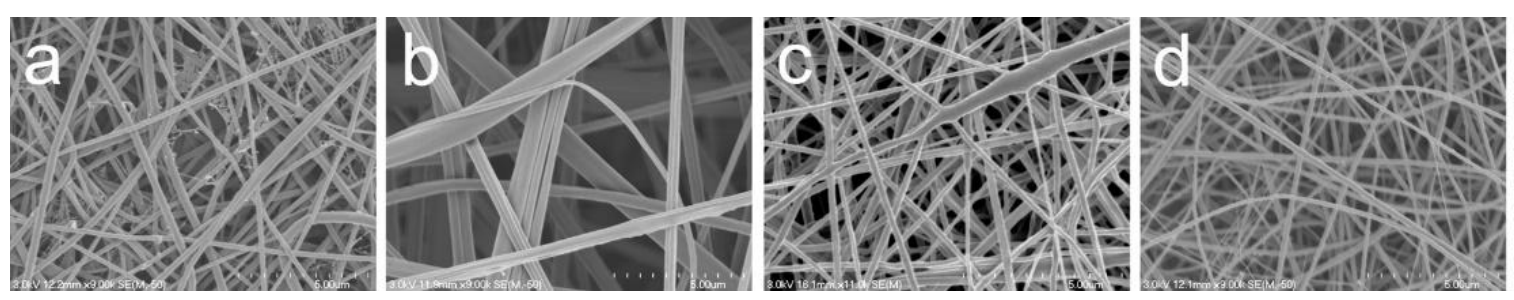

Figure 1: Scanning electron micrographs of electrospun nanofibre veils: (a) PA66, (b) PVB, (c) PCL, (d) PES, (e) PAI. 
Table 2: Test panels and interleaving veils

\begin{tabular}{ccccl}
\hline $\begin{array}{c}\text { Panel } \\
\text { Number }\end{array}$ & $\begin{array}{c}\text { Carbon } \\
\text { Fibre } \\
\text { Volume } \\
\text { Fraction (\%) }\end{array}$ & Veil Polymer & $\begin{array}{c}\text { Veil Areal } \\
\text { Weight } \\
\left(\mathbf{g} / \mathbf{m}^{2}\right)\end{array}$ & Comments \\
\hline 1 & 54.9 & Control & - & Non-interleaved \\
2 & 55.2 & PA66 & 1.5 & 1 ply veil \\
3 & 55.1 & PA66 & 4.5 & 3 ply veil \\
4 & 55.1 & PA66 & 9 & 6 ply veil \\
5 & 54.5 & PA66 and PVB & 9 & 6 ply veil, alternating layers of PA66 nanofibres and PVB microfibres \\
6 & 53.9 & PA66 and PVB & 9 & 6 ply veil, PA66 nanofibres in core, PVB micro fibres on outside \\
7 & 55.1 & PVB & 4.5 & 1 ply veil, microfibres \\
8 & 55.2 & PVB & 4.3 & 2 ply veil, nanofibres \\
9 & 54.9 & PA66 + AgNO 3 & 3.8 & 3 ply veil \\
10 & 55.1 & PCL & 4.2 & 2 ply veil \\
11 & 55.4 & PES & 3.6 & 2 ply veil \\
12 & 54.8 & PAl & 4.1 & 3 ply veil \\
\hline
\end{tabular}


Figure(s)
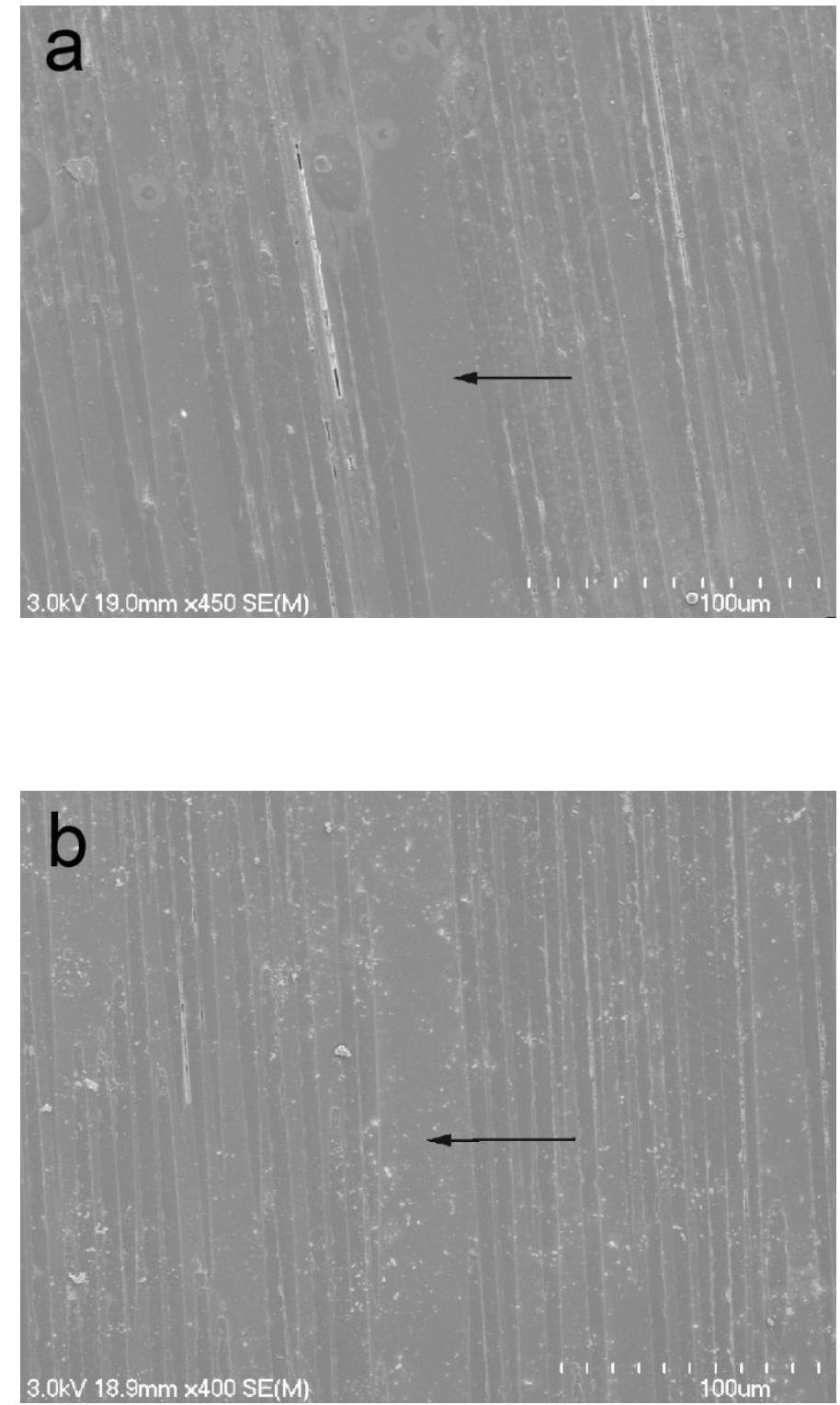


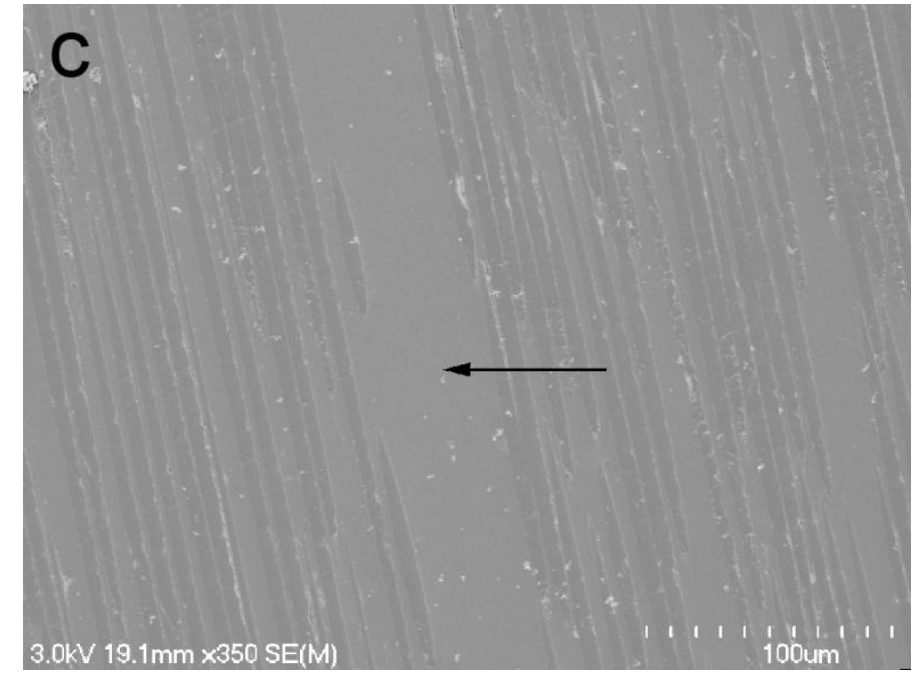

Figure 2: Scanning electron micrographs of laminate cross sections showing interlayers reinforced with: (a) 1.5 $\mathrm{g} / \mathrm{m}^{2}$ PA66 veil, (b) $4.5 \mathrm{~g} / \mathrm{m}^{2}$ PA66 veil, and (c) $9 \mathrm{~g} / \mathrm{m}^{2}$ PA66 veil. Interlayer positions are indicated with an arrow.

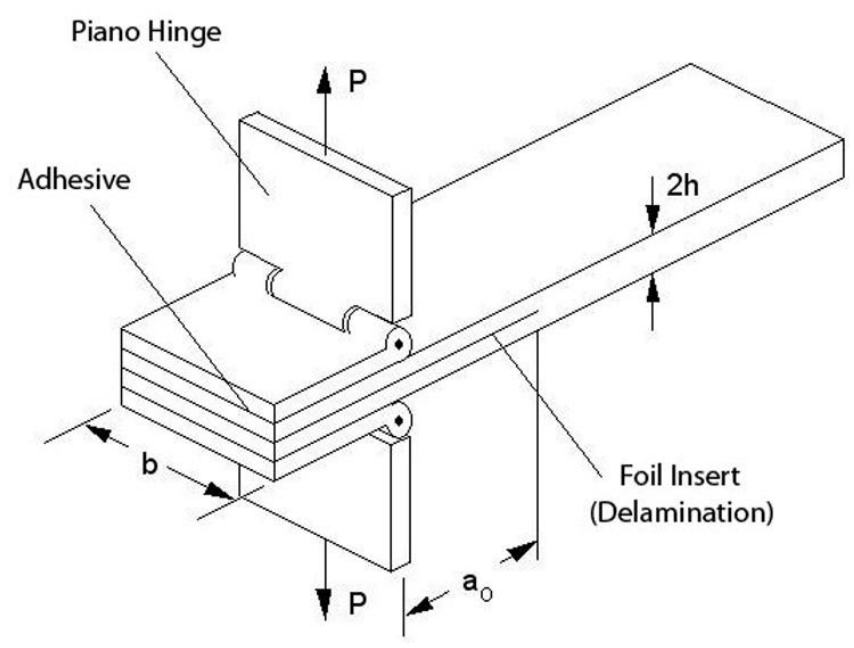

Figure 3: Double Cantilever Beam (DCB) Specimen. 


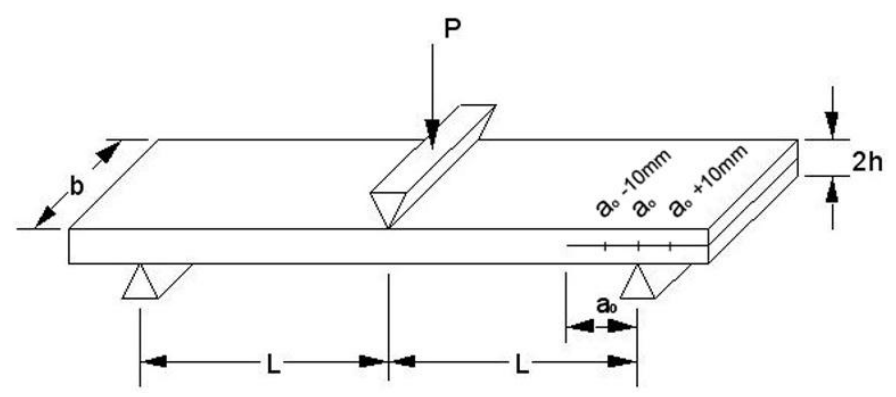

Figure 4: End-notched flexure (ENF) specimen.

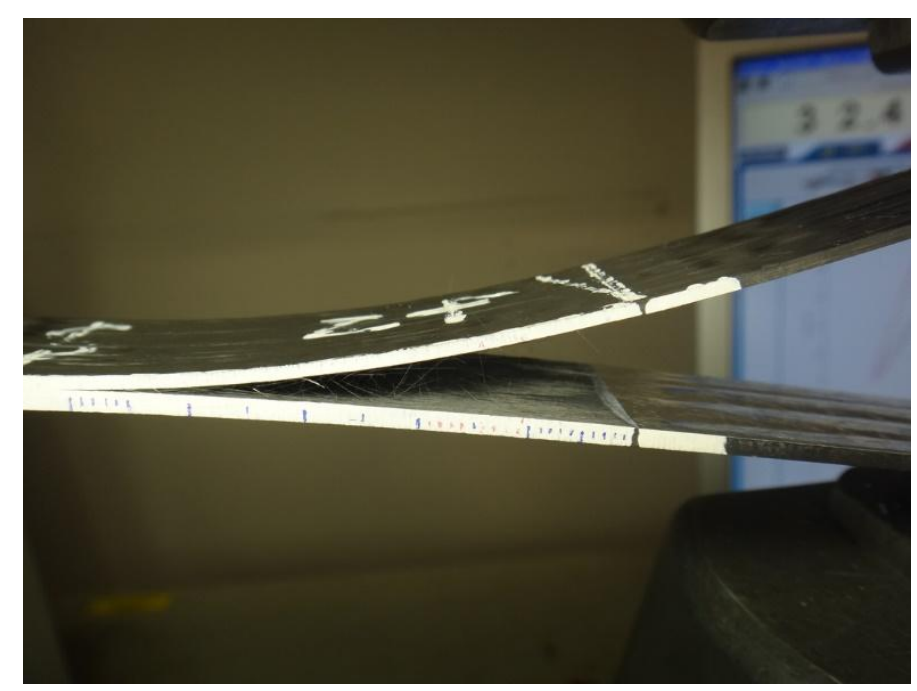

Figure 5: Double Cantilever Beam test showing specimen markings and crack propagation. 


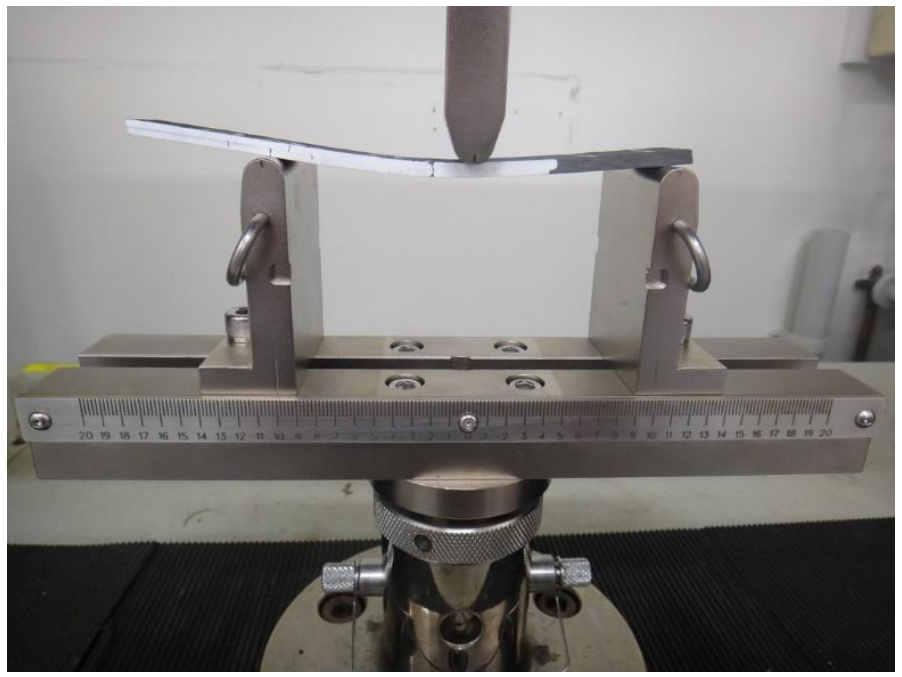

Figure 6: End Notch Flexure Test showing specimen markings and crack propagation.

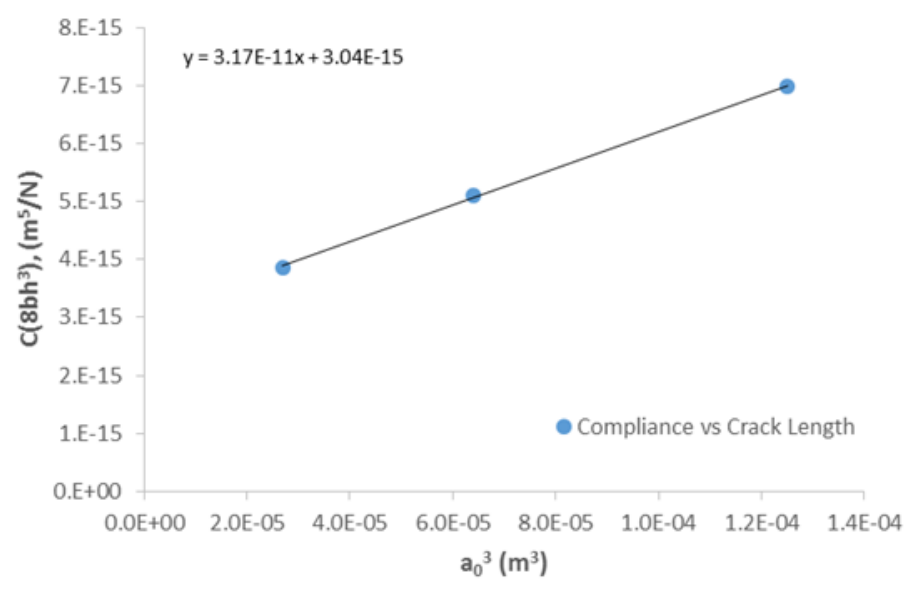

Figure 7: Typical $c\left(8 b h^{3}\right)$ vs. $a_{o}^{3}$ plot 

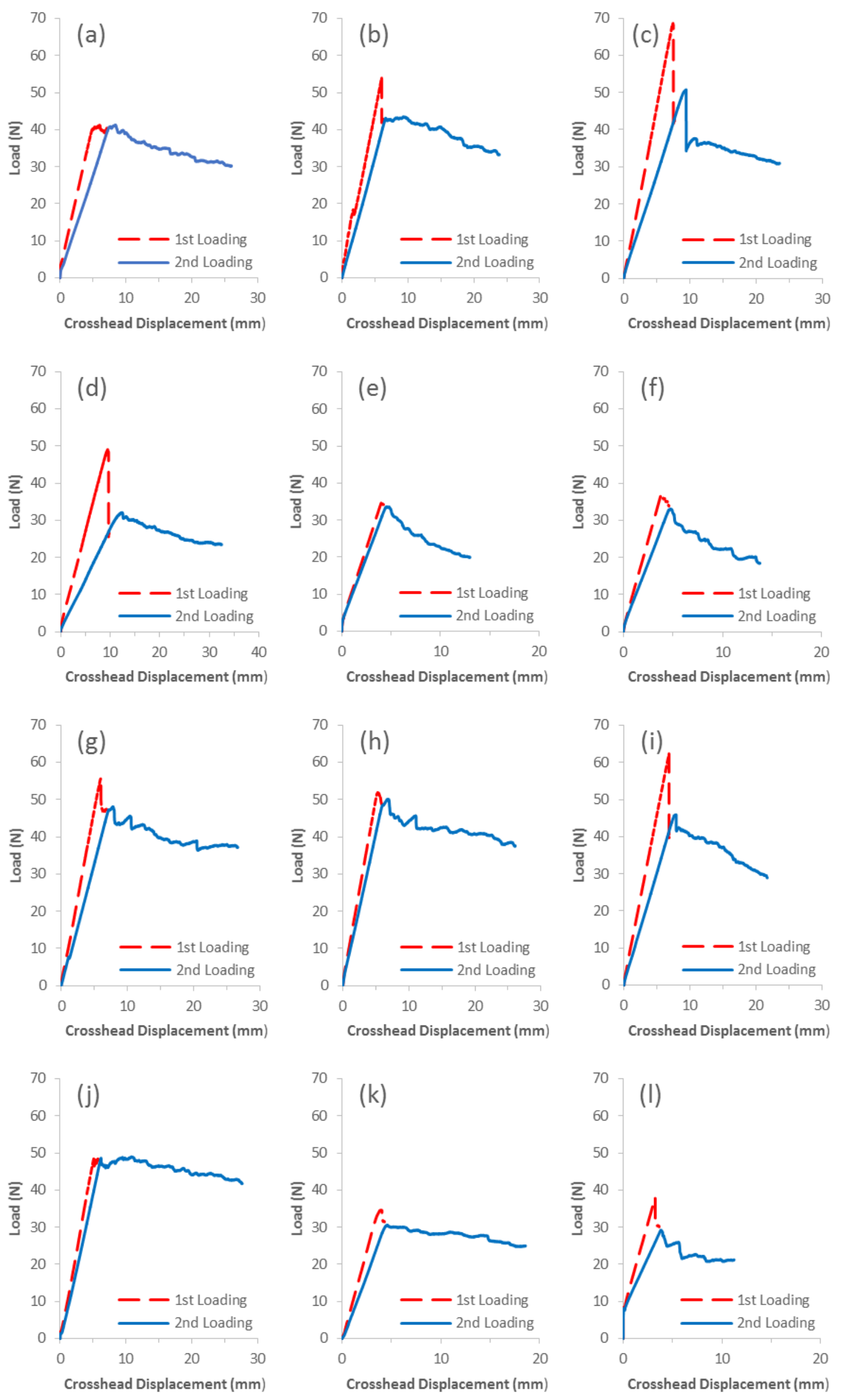

Figure 8: Typical load vs displacement curves for non-interleaved and interleaved DCB test specimens showing two loadings: (a) non-interleaved, (b) $1.5 \mathrm{~g} / \mathrm{m}^{2}$ PA66, (c) $4.5 \mathrm{~g} / \mathrm{m}^{2}$ PA66, (d) $9 \mathrm{~g} / \mathrm{m}^{2}$ PA66, (e) $9 \mathrm{~g} / \mathrm{m}^{2}$ PA66 and PVB alternating layers, (f) $9 \mathrm{~g} / \mathrm{m}^{2}$ PA66 core and PVB skins, (g) $4.5 \mathrm{~g} / \mathrm{m}^{2}$ PVB microfibres, (h) $4.3 \mathrm{~g} / \mathrm{m}^{2}$ PVB nanofibres, (i) $3.8 \mathrm{~g} / \mathrm{m}^{2}$ PA66 $+\mathrm{AgNO}_{3}$, (j) $4.2 \mathrm{~g} / \mathrm{m}^{2} \mathrm{PCL}$, (k) $3.6 \mathrm{~g} / \mathrm{m}^{2}$ PES, (I) $4.1 \mathrm{~g} / \mathrm{m}^{2}$ PAI. 

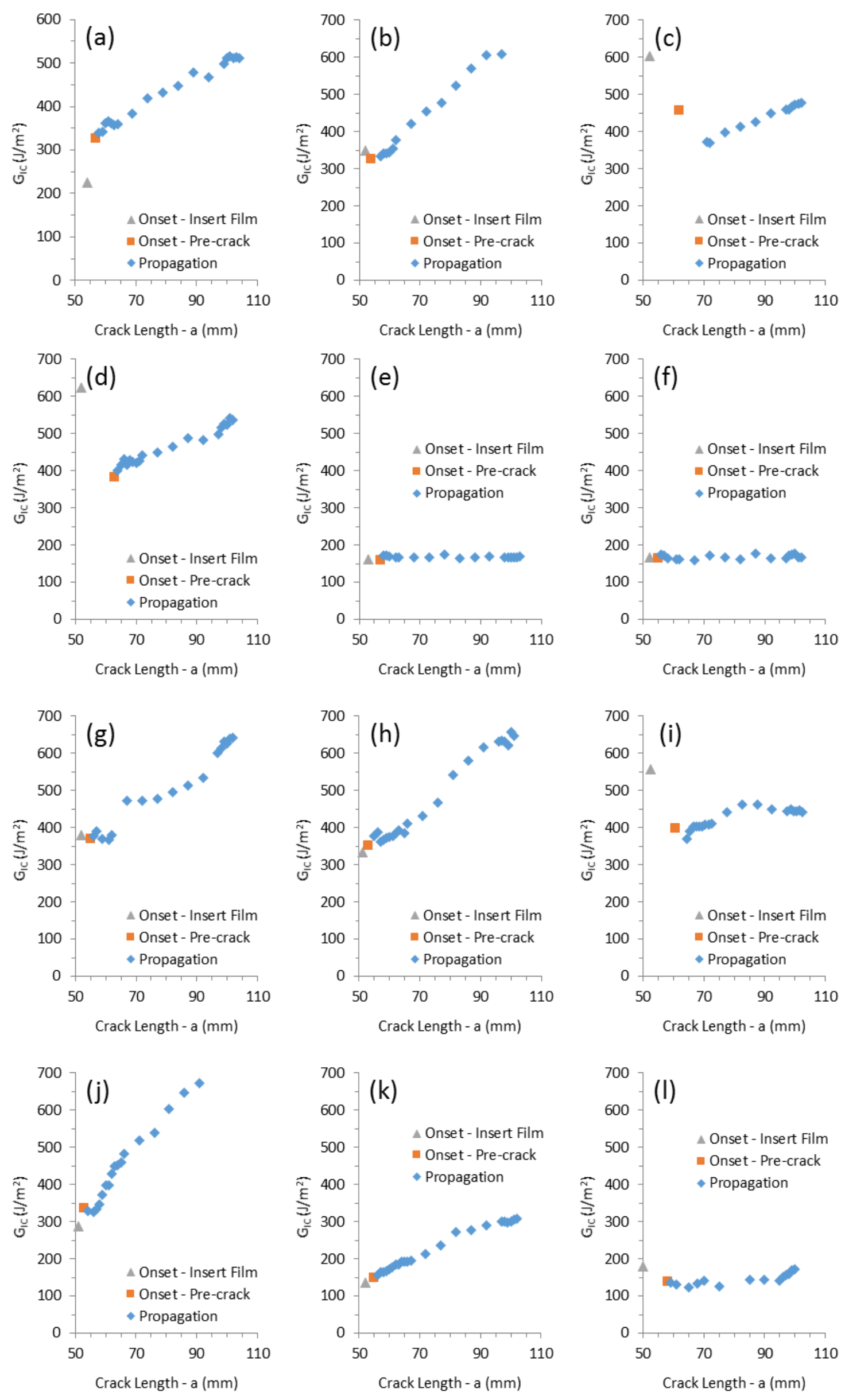

Figure 9: Typical fracture resistance curves for non-interleaved and interleaved DCB test specimens showing the onset Mode I failure at the insert ( $\mathrm{G}_{\mathrm{Ic} \text { - onset }}$ Insert), the onset Mode I failure after the specimen had been pre-cracked ( $\mathrm{G}_{\mathrm{Ic} \text { - onset }}$ Pre-crack), and the Mode I propagation ILFT ( $G_{\mathrm{lc}-\text { Prop }}$ ): (a) non-interleaved, (b) $1.5 \mathrm{~g} / \mathrm{m}^{2}$ PA66, (c) $4.5 \mathrm{~g} / \mathrm{m}^{2} \mathrm{PA} 66$, (d) $9 \mathrm{~g} / \mathrm{m}^{2} \mathrm{PA66},(\mathrm{e}) 9 \mathrm{~g} / \mathrm{m}^{2}$ PA66 and PVB alternating layers, (f) $9 \mathrm{~g} / \mathrm{m}^{2}$ PA66 core and PVB skins, (g) $4.5 \mathrm{~g} / \mathrm{m}^{2}$ PVB microfibres, (h) $4.3 \mathrm{~g} / \mathrm{m}^{2} \mathrm{PVB}$ nanofibres, (i) $3.8 \mathrm{~g} / \mathrm{m}^{2} \mathrm{PA} 66+\mathrm{AgNO}_{3}$, (j) $4.2 \mathrm{~g} / \mathrm{m}^{2} \mathrm{PCL}$, (k) $3.6 \mathrm{~g} / \mathrm{m}^{2} \mathrm{PES}$, (l) $4.1 \mathrm{~g} / \mathrm{m}^{2} \mathrm{PAI}$. 

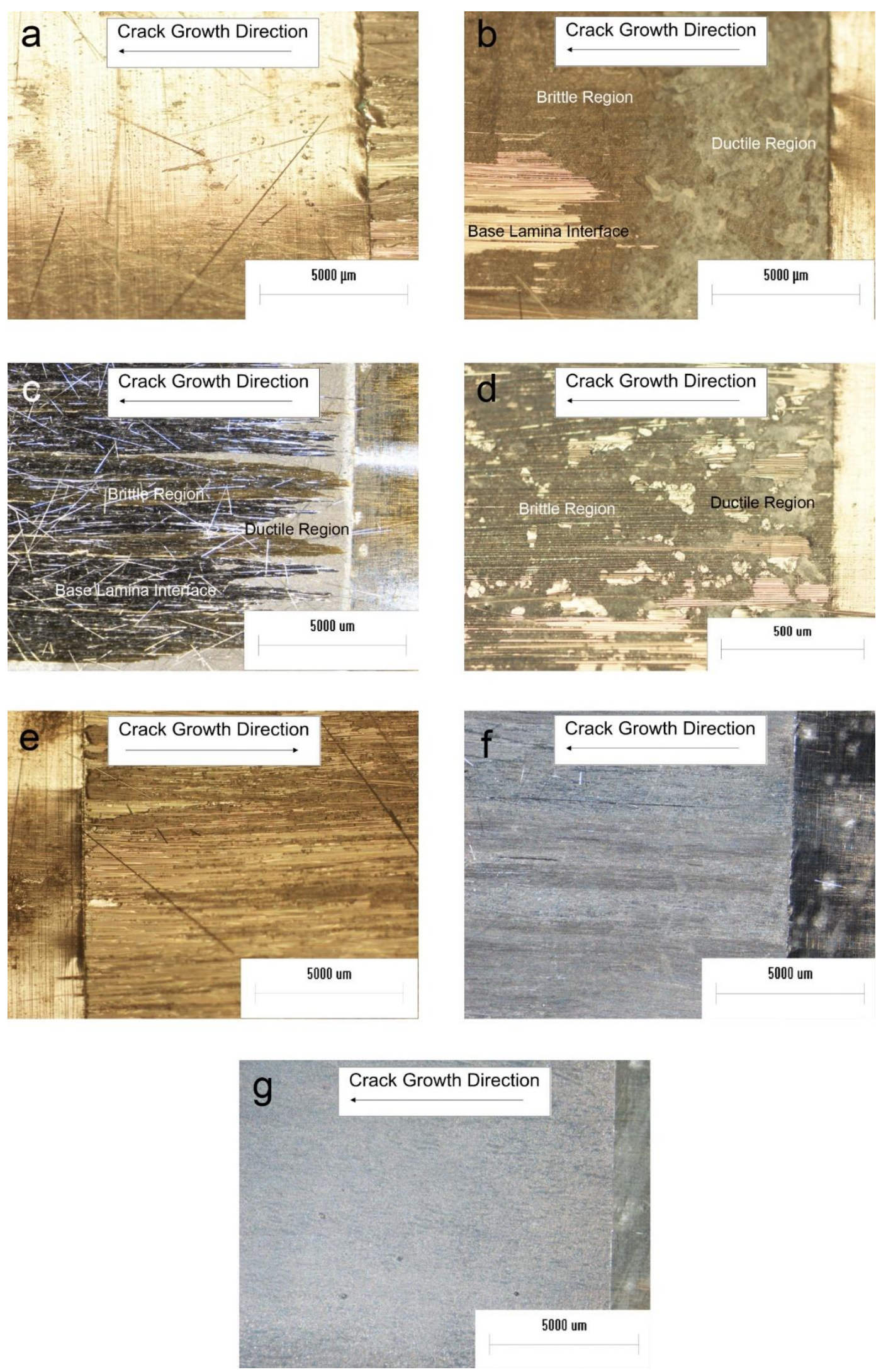

Figure 10: Optical micrographs of DCB specimen fracture surfaces interleaved with: (a) no veil, (b) $9 \mathrm{~g} / \mathrm{m}^{2}$ PA66 veil, (c) $3.8 \mathrm{~g} / \mathrm{m}^{2}$ PA66 + $\mathrm{AgNO}_{3}$ veil, (d) $4.5 \mathrm{~g} / \mathrm{m}^{2}$ PVB nanofiber veil, (e) $4.2 \mathrm{~g} / \mathrm{m}^{2}$ PCL veil, (f) $3.6 \mathrm{~g} / \mathrm{m}^{2}$ PES veil, (g) $4.1 \mathrm{~g} / \mathrm{m}^{2}$ PAl veil. The foil insert can be seen in each image on the side where crack growth was initiated. 
Table 3: Mode I critical strain energy release rate values determined by means of the Modified Beam Theory (MBT).

\begin{tabular}{|c|c|c|c|c|c|}
\hline \multirow[b]{2}{*}{ Nanofibre Veil } & \multicolumn{4}{|c|}{ MBT } & \\
\hline & $\begin{array}{c}G_{1 C} \\
\left(J / m^{2}\right)\end{array}$ & $\begin{array}{l}\text { Std } \\
\text { Dev. }\end{array}$ & $\begin{array}{l}\text { C.V. } \\
\text { (\%) }\end{array}$ & $\begin{array}{l}\text { Improvement } \\
\text { (\%) }\end{array}$ & \\
\hline \multirow{3}{*}{ Non-interleaved } & 234 & 21 & 9.1 & - & $\mathrm{G}_{\mathrm{ic} \text { - onset }}$ Insert \\
\hline & 317 & 63 & 19.9 & - & $\mathrm{G}_{\mathrm{ic} \text { - onset }}$ Pre-crack \\
\hline & 470 & 37 & 8.0 & - & $\mathrm{G}_{\mathrm{ic} \text { - Prop }}$ \\
\hline \multirow{3}{*}{$1.5 \mathrm{~g} / \mathrm{m}^{2}$ PA66 } & 363 & 14 & 3.9 & 55 & $\mathrm{G}_{\mathrm{ic} \text { - onset }}$ Insert \\
\hline & 326 & 20 & 6.1 & 3 & $\mathrm{G}_{\mathrm{ic} \text { - onset }}$ Pre-crack \\
\hline & 446 & 26 & 5.8 & -5 & $\mathrm{G}_{\mathrm{ic} \text { - Prop }}$ \\
\hline \multirow{3}{*}{$4.5 \mathrm{~g} / \mathrm{m}^{2}$ PA66 } & 600 & 27 & 4.4 & 156 & $\mathrm{G}_{\mathrm{ic} \text { - onset }}$ Insert \\
\hline & 423 & 38 & 9.0 & 34 & $\mathrm{G}_{\mathrm{ic} \text { - onset }}$ Pre-crack \\
\hline & 442 & 26 & 5.9 & -6 & $\mathrm{G}_{\mathrm{ic} \text { - Prop }}$ \\
\hline \multirow{3}{*}{$9 \mathrm{~g} / \mathrm{m}^{2}$ PA66 } & 639 & 50 & 7.9 & 173 & $\mathrm{G}_{\mathrm{ic} \text { - onset }}$ Insert \\
\hline & 352 & 26 & 7.4 & 11 & $\mathrm{G}_{\mathrm{ic} \text { - onset }}$ Pre-crack \\
\hline & 440 & 33 & 7.6 & -6 & $\mathrm{G}_{\mathrm{ic} \text { - Prop }}$ \\
\hline \multirow{3}{*}{$\begin{array}{l}9 \mathrm{~g} / \mathrm{m}^{2} \mathrm{PA} 66 \text { and PVB } \\
\text { alternating layers }\end{array}$} & 156 & 7 & 4.8 & -33 & $\mathrm{G}_{\text {ic - onset }}$ Insert \\
\hline & 164 & 14 & 8.7 & -48 & $\mathrm{G}_{\mathrm{ic} \text { - onset }}$ Pre-crack \\
\hline & 172 & 7 & 4.1 & -63 & $\mathrm{G}_{\text {ic - Prop }}$ \\
\hline \multirow{3}{*}{$\begin{array}{c}9 \mathrm{~g} / \mathrm{m}^{2} \text { PA66 core and } \\
\text { PVB skins }\end{array}$} & 172 & 25 & 14.5 & -26 & $\mathrm{G}_{\mathrm{ic} \text { - onset }}$ Insert \\
\hline & 165 & 7 & 4.5 & -48 & $\mathrm{G}_{\mathrm{ic} \text { - onset }}$ Pre-crack \\
\hline & 169 & 1 & 0.4 & -64 & $\mathrm{G}_{\mathrm{ic}-\mathrm{Prop}}$ \\
\hline \multirow{3}{*}{$\begin{array}{c}4.5 \mathrm{~g} / \mathrm{m}^{2} \mathrm{PVB} \\
\text { microfibres }\end{array}$} & 379 & 24 & 6.4 & 62 & $\mathrm{G}_{\mathrm{ic} \text { - onset }}$ Insert \\
\hline & 359 & 44 & 12.2 & 13 & $\mathrm{G}_{\mathrm{ic} \text { - onset }}$ Pre-crack \\
\hline & 491 & 38 & 7.8 & 5 & $\mathrm{G}_{\mathrm{ic} \text { - Prop }}$ \\
\hline \multirow{3}{*}{$\begin{array}{c}4.3 \mathrm{~g} / \mathrm{m}^{2} \mathrm{PVB} \\
\text { nanofibres }\end{array}$} & 358 & 53 & 14.8 & 53 & $\mathrm{G}_{\mathrm{ic} \text { - onset }}$ Insert \\
\hline & 369 & 33 & 9.1 & 16 & $\mathrm{G}_{\mathrm{ic} \text { - onset }}$ Pre-crack \\
\hline & 521 & 98 & 18.9 & 11 & $\mathrm{G}_{\text {ic - Prop }}$ \\
\hline \multirow{3}{*}{$\begin{array}{c}3.8 \mathrm{~g} / \mathrm{m}^{2} \mathrm{PA} 66+ \\
\mathrm{AgNO}_{3}\end{array}$} & 530 & 64 & 12.2 & 126 & $\mathrm{G}_{\mathrm{ic} \text { - onset }}$ Insert \\
\hline & 370 & 23 & 6.4 & 17 & $\mathrm{G}_{\mathrm{ic} \text { - onset }}$ Pre-crack \\
\hline & 432 & 72 & 16.8 & -8 & $\mathrm{G}_{\mathrm{ic} \text { - Prop }}$ \\
\hline \multirow{3}{*}{$4.2 \mathrm{~g} / \mathrm{m}^{2} \mathrm{PCL}$} & 267 & 20 & 7.5 & 14 & $\mathrm{G}_{\mathrm{ic} \text { - onset }}$ Insert \\
\hline & 328 & 13 & 4.0 & 4 & $\mathrm{G}_{\mathrm{ic} \text { - onset }}$ Pre-crack \\
\hline & 525 & 89 & 17.0 & 12 & $\mathrm{G}_{\mathrm{ic} \text { - Prop }}$ \\
\hline \multirow{3}{*}{$3.6 \mathrm{~g} / \mathrm{m}^{2} \mathrm{PES}$} & 132 & 35 & 26.7 & -44 & $\mathrm{G}_{\mathrm{ic} \text { - onset }}$ Insert \\
\hline & 152 & 30 & 19.4 & -52 & $\mathrm{G}_{\mathrm{ic} \text { - onset }}$ Pre-crack \\
\hline & 225 & 80 & 35.7 & -52 & $\mathrm{G}_{\mathrm{ic} \text { - Prop }}$ \\
\hline \multirow{3}{*}{$4.1 \mathrm{~g} / \mathrm{m}^{2} \mathrm{PAl}$} & 149 & 29 & 19.1 & -36 & $\mathrm{G}_{\mathrm{ic} \text { - onset }}$ Insert \\
\hline & 133 & 6 & 4.7 & -58 & $\mathrm{G}_{\mathrm{ic} \text { - onset }}$ Pre-crack \\
\hline & 150 & 31 & 20.4 & -68 & $\mathrm{G}_{\mathrm{ic} \text { - Prop }}$ \\
\hline
\end{tabular}




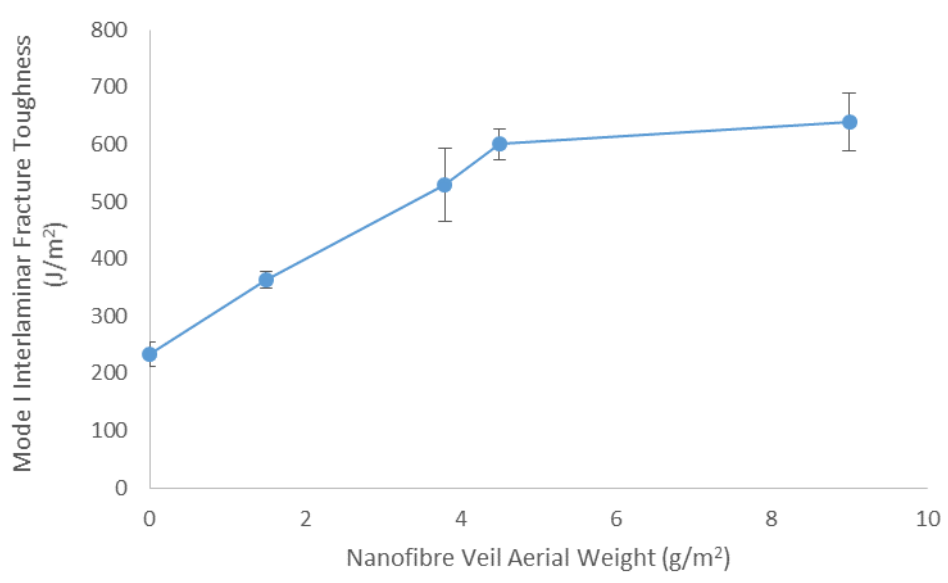

Figure 11: Mode I interlaminar fracture toughness ( $G_{I c}$ - onset Insert) for composites interleaved with various PA66 veils. Error bars represent \pm 1 standard deviation.

Table 4: Mode II critical strain energy release rate values.

\begin{tabular}{|c|c|c|c|c|}
\hline Nanofibre Veil & $\begin{array}{l}G_{\| l} \\
\left(\mathrm{~J} / \mathrm{m}^{2}\right)\end{array}$ & Std Dev. & $\begin{array}{l}\text { C.V. } \\
\text { (\%) }\end{array}$ & $\begin{array}{l}\text { Improvement } \\
\text { (\%) }\end{array}$ \\
\hline Non-interleaved & 1284 & 254 & 19.8 & - \\
\hline $1.5 \mathrm{~g} / \mathrm{m}^{2} \mathrm{PA} 66$ & 1658 & 249 & 15.0 & 29 \\
\hline $4.5 \mathrm{~g} / \mathrm{m}^{2} \mathrm{PA} 66$ & 2173 & 196 & 9.0 & 69 \\
\hline $9 \mathrm{~g} / \mathrm{m}^{2}$ PA66 & 1983 & 208 & 10.5 & 54 \\
\hline $\begin{array}{l}9 \mathrm{~g} / \mathrm{m}^{2} \text { PA66 and PVB } \\
\text { alternating layers }\end{array}$ & 1863 & 516 & 27.7 & 45 \\
\hline $\begin{array}{c}9 \mathrm{~g} / \mathrm{m}^{2} \text { PA66 } 6 \text { core and PVB } \\
\text { skins }\end{array}$ & 1902 & 499 & 26.3 & 48 \\
\hline $4.5 \mathrm{~g} / \mathrm{m}^{2}$ PVB microfibres & 1186 & 166 & 14.0 & -8 \\
\hline $4.3 \mathrm{~g} / \mathrm{m}^{2} \mathrm{PVB}$ nanofibres & 1213 & 270 & 22.2 & -6 \\
\hline $3.8 \mathrm{~g} / \mathrm{m}^{2} \mathrm{PA} 66+\mathrm{AgNO}_{3}$ & 1748 & 201 & 11.5 & 36 \\
\hline $4.2 \mathrm{~g} / \mathrm{m}^{2} \mathrm{PCL}$ & 1370 & 307 & 22.4 & 7 \\
\hline $3.6 \mathrm{~g} / \mathrm{m}^{2} \mathrm{PES}$ & 1541 & 277 & 18.0 & 20 \\
\hline $4.1 \mathrm{~g} / \mathrm{m}^{2} \mathrm{PAI}$ & 2006 & 376 & 18.8 & 56 \\
\hline
\end{tabular}




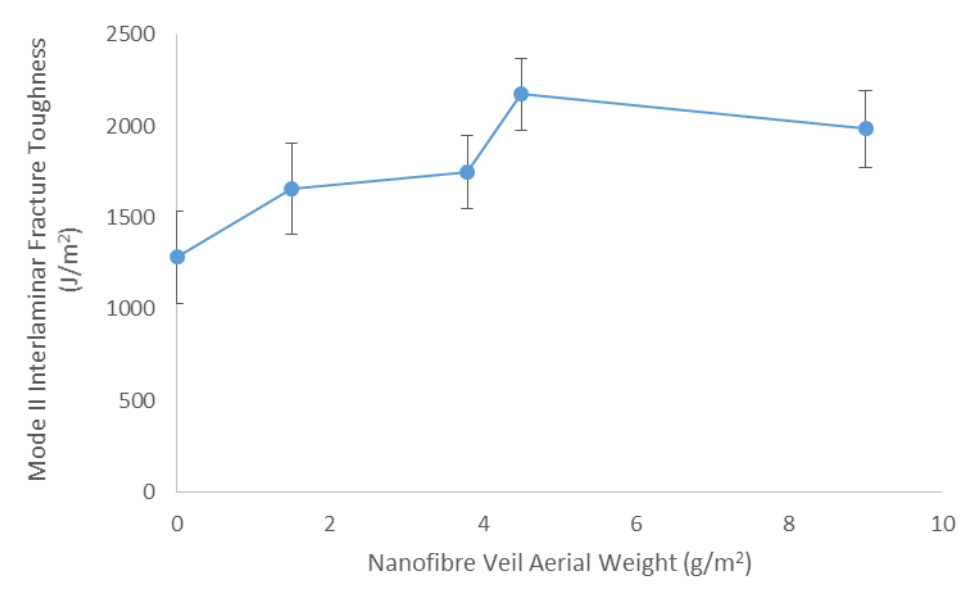

Figure 12: Mode II interlaminar fracture toughness $\left(G_{\| C}\right)$ for composites interleaved with various PA66 veils. Error bars represent \pm 1 standard deviation. 